\title{
Dissolution of Rare Earth Elements from Coal Fly Ash Particles in a Dilute $\mathrm{H}_{2} \mathrm{SO}_{4}$ Solvent
}

\author{
Shunsuke Kashiwakura ${ }^{1 *}$, Yuichi Kumagai ${ }^{2}$, Hiroshi Kubo ${ }^{3}$, Kazuaki Wagatsuma ${ }^{1}$ \\ ${ }^{1}$ Institute for Materials Research, Tohoku University, Sendai, Japan \\ ${ }^{2}$ Soma Environmental Service, Co., Ltd., Soma, Fukushima, Japan \\ ${ }^{3}$ Technical Research Institute of Obayashi Corpolation, Kiyose, Tokyo, Japan \\ Email: ${ }^{*}$ shunsuke-k@imr.tohoku.ac.jp
}

Received January 10, 2013; revised February 20, 2013; accepted March 20, 2013

Copyright (C) 2013 Shunsuke Kashiwakura et al. This is an open access article distributed under the Creative Commons Attribution License, which permits unrestricted use, distribution, and reproduction in any medium, provided the original work is properly cited.

\begin{abstract}
Recently, the worldwide supply of rare earth element (REE) resources will be severely restricted. On the other hand, coal fly ash particles emitted from coal-fired electric power plants contain relatively high concentrations of REEs. The contents of REEs in coal fly ash are regularly several hundreds of ppmw. In order to extract and recover REEs from coal fly ash particles, as a first step, we have investigated their dissolution behavior in a dilute $\mathrm{H}_{2} \mathrm{SO}_{4}$ solvent. The REE content of coal fly ash specimens has been precisely determined, and their presence in the ash component of the original coal and their enrichment in coal fly ash particles during coal combustion have been suggested. REEs in coal fly ash dissolve gradually in $\mathrm{H}_{2} \mathrm{SO}_{4}$ over time, and this implies two types of occurrences of the REEs in coal fly ash particles. By applying the unreacted core model to the dissolution behavior of REEs in a $\mathrm{H}_{2} \mathrm{SO}_{4}$ solvent, we can explain both types of occurrences.
\end{abstract}

Keywords: Coal Fly Ash; Rare Earth Elements; Dissolution Behavior; Unreacted Core Model

\section{Introduction}

Currently, electricity generated from coal combustion accounts for around $25 \%$ of the total power generation in Japan. Since the energy supply, including electricity, is heavily dependent on imported resources, coal occupies an important position in Japan's electricity generation. Since a reduction in the proportion of electricity generated by nuclear power stations is unavoidable, owing to the disaster at the Fukushima Daiichi nuclear power stations, the utilization of coal-fired thermal electric power stations will become more important.

However, coal-fired power plants are recognized as an emission source of regulated substances such as coal ash; this is a hazardous industrial waste emitted from power plants, and in Japan, $10 \mathrm{Mt}$ of coal ash is emitted per year [1]. Coal fly ash accounts for around $85 \%-95 \%$ of the total coal ash emission [2] and has been widely recycled and used mainly as a raw material of fly ash cement in order to minimize landfill and to comply with the Basic Act for the Promotion of the Recycling-Oriented Society, enforced since 2000 [3].

Coal fly ash contains various trace elements [4], some

${ }^{*}$ Corresponding author. of which are recognized to be hazardous. The hazardous inorganic substances include arsenic, boron, cadmium, fluorine, hexavalent chromium, mercury, lead, and selenium; their contents and the elution concentrations are strictly regulated by the Environmental Basic Act and its corresponding legislation $[5,6]$.

Hence, the reduction of the hazardous components eluted from coal fly ash particles is necessary for their recycling. For this purpose, we have developed an acidwashing process [7-9]. The aim of this process is to remove the above-mentioned soluble regulated substances, focused on in our previous studies, from coal fly ash by dissolving them in an acid solvent. We showed that their dissolution, adsorption, and re-elution behavior depends strongly on the $\mathrm{pH}$ of the acid solutions and were successful in decreasing elution concentrations below regulatory limits.

In recent years, rare earth elements (REEs) have been recognized as important materials since they are widely utilized in the production of magnets, fluorescent materials, laser crystals, etc. [10]. Since Japan has been the largest consumer of REE products, exploration into alternative supply routes is important for resource security.

Coal fly ash contains relatively high concentrations of 
REEs. For example, NIST SRM 1633b and IRANT EOP, which are the standard reference materials for coal fly ash, contain $420 \mathrm{mg} \cdot \mathrm{kg}^{-1}$ and $806 \mathrm{mg} \cdot \mathrm{kg}^{-1}$ of REEs, respectively. Although these values are lower than those in ion-adsorbed type ore, they are equivalent to monaziteor bastnaesite-type ore [11].

REEs are known to be soluble in an acidic solvent. Figure 1 shows the Pourbaix diagram for europium, as a typical example of a REE. It is clear that europium is soluble in acid as $\mathrm{Eu}^{3+}$, implying that REEs may be recovered from coal fly ash particles. In this paper, we will discuss the dissolution behavior of REEs in dilute acidic solvents in order to examine the feasibility of REE recovery using an acid-washing process.

\section{Materials and Methods}

\subsection{Coal Fly Ash Specimens Utilized in This Study}

Three types of coal fly ash specimens, Ash-A, Ash-B, and IRANT EOP, have been used in this work, and their compositions are listed in Table 1. Ash-A and Ash-B were provided by an electrical power company in Soma City, Fukushima Prefecture, Tohoku Region, Japan. As in the case of general coal fly ash [12], these specimens mainly consist of quartz $\left(\mathrm{SiO}_{2}\right)$, mullite $\left(3 \mathrm{Al}_{2} \mathrm{O}_{3} \cdot 2 \mathrm{SiO}_{2}\right)$, and amorphous solids. The average diameter of the ash specimens was several tens of micrometers. IRANT EOP was obtained as a standard reference material from the Institute of Radioecology and Applied Nuclear Techni-

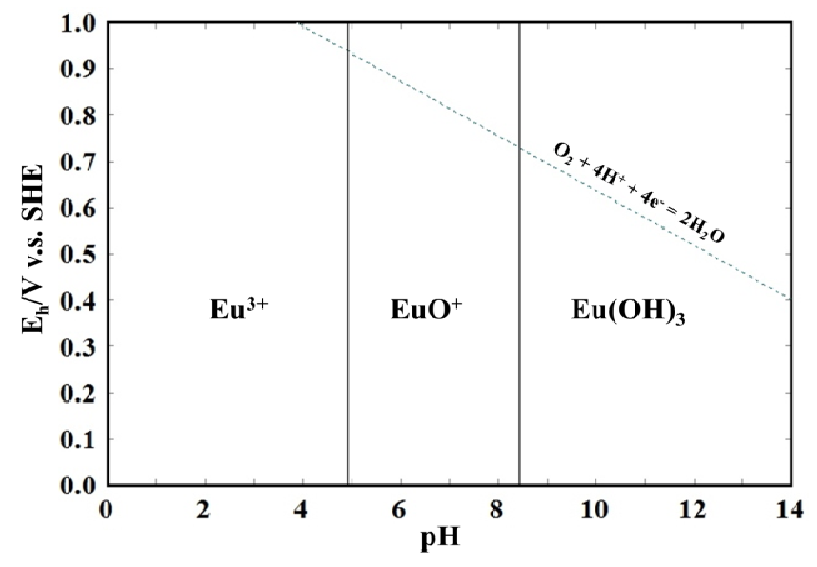

Figure 1. A pourvaix diagram for europium.

Table 1. Chemical compositions of coal fly ash specimens obtained by XRF analysis.

\begin{tabular}{ccccccccc}
\hline Contents $/ \%$ & $\mathrm{SiO}_{2}$ & $\mathrm{Al}_{2} \mathrm{O}_{3}$ & $\mathrm{Fe}_{2} \mathrm{O}_{3}$ & $\mathrm{CaO}$ & $\mathrm{MgO}$ & $\mathrm{Na}_{2} \mathrm{O}$ & $\mathrm{K}_{2} \mathrm{O}$ & $\mathrm{TiO}_{2}$ \\
\hline Ash-A & 71.8 & 21.7 & 1.66 & 1.07 & 0.42 & $0.38 \mathrm{~s}$ & 1.36 & 0.75 \\
Ash-B & 62.2 & 20.8 & 3.44 & 8.52 & 1.57 & 0.37 & 1.14 & 0.65 \\
Ash-EOP & 49.1 & 29.8 & 7.37 & 2.35 & 0.97 & 0.50 & 0.77 & 6.02 \\
\hline
\end{tabular}

niques, Slovakia, and it has certified concentrations of lanthanum, cerium, and europium, and informative concentrations for scandium, samarium, terbium, ytterbium, lutetium (with expanded uncertainties), dysprosium, gadolinium, neodymium, praseodymium, and yttrium (without expanded uncertainties).

\subsection{Reagents and Experimental Procedure}

In order to determine the REE concentrations in Ash-A and Ash-B and to verify the accuracy of the measurements obtained by inductively coupled plasma mass spectrometry (ICP-MS), the REE concentrations in the specimens were determined by means of acid digestion. Around $0.1 \mathrm{~g}$ of each specimen was put into a Teflon beaker. Reagent grade concentrated hydrochloric acid (35 wt\%), nitric acid (60 wt\%), and hydrofluoric acid (48 wt $\%), 10 \mathrm{ml}$ each, were added. Two solutions were prepared for each ash specimen. They were then heated at $200^{\circ} \mathrm{C}$ for $6 \mathrm{~h}$ on a hot plate. After air-cooling, $10 \mathrm{~mL}$ of $\mathrm{H}_{2} \mathrm{SO}_{4}(95 \mathrm{wt} \%)$ were added and heated again to remove any fluorine, originating from the hydrofluoric acid, by vaporization of $\mathrm{SiF}_{4}(\mathrm{~g})$. After confirming the generation of $\mathrm{H}_{2} \mathrm{SO}_{4}$ fumes, indicating the complete vaporization of the fluorine content, they were again air-cooled. At this time, white residual dross, which may be $\mathrm{CaSO}_{4}$, was observed in the solutions of Ash-B. The solutions were moved to $100 \mathrm{~mL}$ volumetric flasks, and at this point, the residual dross in the solutions had completely dissolved. After complete digestion, with the dissolution of the white residual dross visually confirmed, the solutions were prepared for measurement with inductively coupled plasma-mass spectrometry (ICP-MS; HP4500, Agilent) using an internal standard technique involving the addition of $0.2 \mathrm{mg} \cdot \mathrm{L}^{-1}$ of rhenium.

The equipment for the dissolution test comprised a Pyrex beaker, a magnetic stirrer, a heater with a stirring magnet, electrodes that were used to monitor the $\mathrm{pH}$, redox potential, and temperature of the solutions, and a laptop computer. Five grams of each coal fly ash specimen were agitated with $500 \mathrm{~mL}$ of the $\mathrm{H}_{2} \mathrm{SO}_{4}$ solvent, which was diluted at 10 times using ultrapure water. The solutions were agitated at $30^{\circ} \mathrm{C}, 60^{\circ} \mathrm{C}$, and $80^{\circ} \mathrm{C}$ for $2 \mathrm{~h}$. During agitation, the solutions were periodically sampled at $5,10,30,60$, and $120 \mathrm{~min}$. The sampling of the solutions was conducted using a $10 \mathrm{~mL}$ macropipette. The aliquot was then filtered within $30 \mathrm{~s}$, and $5 \mathrm{~mL}$ of each filtrate was diluted to $50 \mathrm{~mL}$ in a volumetric flask. ICPMS measurements were then conducted for the solutions with the rhenium internal standard described earlier.

\section{Results}

\subsection{The Determination of REE Elements in Coal Fly Ash}

Table 2 summarizes the REE contents in IRANT EOP. 
The calibration line for the measured REEs was prepared in the range of $1-1000 \mu \mathrm{g} \mathrm{L}-1$. The variance of all calibration lines is 1.00 . The values of the REE concentrations are expressed as the mean value $\pm(2 \times$ standard deviation). Since the true values of the REE concentrations are unknown, the recovery rate was calculated using averaged values as shown in Equation (1).

Recovery rate $=$

$\underline{\left(\text { Determined mean value in } \mathrm{mg} \cdot \mathrm{kg}^{-1} \times 100\right)}$

(Certified mean value in $\mathrm{mg} \cdot \mathrm{kg}^{-1}$ )

The range of the calculated recovery rates are $92 \%$ $118 \%$ for $\mathrm{La}, \mathrm{Ce}$, and $\mathrm{Eu}$, for which IRANT EOP has certified values, and $72 \%-133 \%$ for $\mathrm{Sc}, \mathrm{Sm}, \mathrm{Tb}, \mathrm{Yb}$, $\mathrm{Lu}, \mathrm{Y}, \mathrm{Pr}, \mathrm{Nd}, \mathrm{Gd}$, and Dy, for which IRANT EOP has informative values. Iwata et al. [13] also determined REE components in the coal fly ash referenced standard material, NIST $1633 \mathrm{~b}$. Their recovery values were $48 \%-123 \%$ for informative values, and $76 \%-83 \%$ by comparison with the literature $[14,15]$. From this, the measured values of REE concentrations were considered to be reasonably well determined. The accuracy of the REE concentrations in coal fly ash determined using the acid-digestion method with hydrofluoric acid and subsequent ICP-MS measurement is considered to be adequate, and results for Ash-A and Ash-B are shown in Table 3.

\subsection{The Dissolution Behavior of REEs in Coal Fly Ash Specimens}

As typical examples, the dissolution behaviors of lanthanum, cerium, europium, and samarium in a dilute $\mathrm{H}_{2} \mathrm{SO}_{4}$ solvent are displayed in Figure 2. The dissolution rate was calculated by (dissolved mass of $\mathrm{X}$ in $\mu \mathrm{g} \times 100$ / content of $X$ in $\mu \mathrm{g}$ ), where the content of $X$ was determined in the previous section. During the dissolution test, the values of the $\mathrm{pH}$ and redox potential for each solution were kept below 0 and above $800 \mathrm{mV}$ (vs the standard hydrogen electrode (SHE)), respectively. The dissolution rates are seen to increase when the temperature of the $\mathrm{H}_{2} \mathrm{SO}_{4}$ solution increases, and the dissolution rates of Ash-B are higher than those of Ash-A. The other REEs, i.e., cerium, scandium, yttrium, praseodymium, neodymium, samarium, gadolinium, europium, terbium, dysprosium, holmium, erbium, thulium, ytterbium, and lutetium

Table 2. Comparison of the determined REE contents in IRANT EOP.

\begin{tabular}{|c|c|c|c|c|c|}
\hline & $\mathrm{La}$ & $\mathrm{Ce}$ & $\mathrm{Eu}$ & & \\
\hline EOP (This study, $\mathrm{mg} \cdot \mathrm{kg}^{-1}$ ) & $148 \pm 8$ & $310 \pm 3$ & $5.1 \pm 0.7$ & & \\
\hline EOP (Certified, $\left.\mathrm{mg} \cdot \mathrm{kg}^{-1}\right)$ & $164 \pm 9$ & $322 \pm 21$ & $4.99 \pm 0.77$ & & \\
\hline \multirow[t]{2}{*}{ Recovery rate $/ \%$} & 90 & 96 & 102 & & \\
\hline & $\mathrm{Sc}$ & $\mathrm{Sm}$ & $\mathrm{Tb}$ & $\mathrm{Yb}$ & $\mathrm{Lu}$ \\
\hline EOP (This study, $\mathrm{mg} \cdot \mathrm{kg}^{-1}$ ) & $28.9 \pm 2.3$ & $17.4 \pm 1.8$ & $2.0 \pm 0.38$ & $2.7 \pm 0.32$ & $0.4 \pm 0.06$ \\
\hline \multirow[t]{2}{*}{ Recovery rate $/ \%$} & 79 & 79 & 103 & 62 & 76 \\
\hline & $\mathrm{Y}$ & $\operatorname{Pr}$ & $\mathrm{Nd}$ & $\mathrm{Gd}$ & Dy \\
\hline EOP (This study, $\mathrm{mg} \cdot \mathrm{kg}^{-1}$ ) & 34.3 & 29.4 & 112 & 21.1 & 8.3 \\
\hline EOP (Informative, $\mathrm{mg} \cdot \mathrm{kg}^{-1}$ ) & 30 & 30 & 150 & 20 & 10 \\
\hline Recovery rate $/ \%$ & 114 & 98 & 75 & 106 & 83 \\
\hline
\end{tabular}

Table 3. Determined REE contents in Ash-A and Ash-B.

\begin{tabular}{|c|c|c|c|c|}
\hline Contents $/ \mathrm{mg} \cdot \mathrm{kg}^{-1}$ & $\mathrm{Sc}$ & $\mathrm{Y}$ & $\mathrm{La}$ & $\mathrm{Ce}$ \\
\hline Ash-A & 12.7 & 71 & 49.8 & 123 \\
\hline Ash-B & 13.5 & 51 & 54.2 & 117 \\
\hline Contents $/ \mathrm{mg} \cdot \mathrm{kg}^{-1}$ & $\operatorname{Pr}$ & $\mathrm{Nd}$ & $\mathrm{Sm}$ & $\mathrm{Eu}$ \\
\hline Ash-A & 14.5 & 62 & 16.8 & 3.2 \\
\hline Ash-B & 13.4 & 54 & 10.8 & 2.4 \\
\hline Contents $/ \mathrm{mg} \cdot \mathrm{kg}^{-1}$ & $\mathrm{Gd}$ & $\mathrm{Tb}$ & Dy & Ho \\
\hline Ash-A & 15.6 & 2.5 & 14.4 & 2.7 \\
\hline Ash-B & 9.3 & 1.5 & 8.8 & 1.7 \\
\hline Contents $/ \mathrm{mg} \cdot \mathrm{kg}^{-1}$ & Er & $\mathrm{Tm}$ & $\mathrm{Yb}$ & $\mathrm{Lu}$ \\
\hline Ash-A & 8.7 & 1.0 & 7.7 & 1.0 \\
\hline Ash-B & 5.7 & 0.7 & 5.4 & 0.7 \\
\hline
\end{tabular}




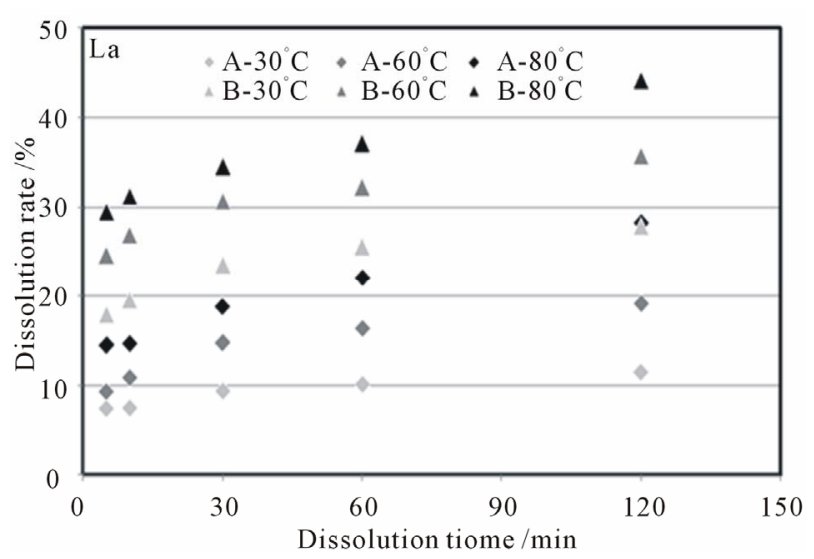

Figure 2. Changes in dissolution rates of lanthanum from Ash-A or Ash-B in a dilute $\mathrm{H}_{2} \mathrm{SO}_{4}$ solvent.

show dissolution behavior quite similar to lanthanum shown in Figure 2.

\section{Discussions}

\subsection{The Probability of Surface Deposition of REEs}

The distribution of lanthanides in rocks or ores are known to follow the Oddo-Harkins rule; i.e., that atoms with even atomic numbers are more stable than those with odd numbers because their nuclei are more tightly bound. Figure 3 shows the lanthanide contents in three coal fly ash specimens, and they completely conform to this rule since the lanthanides with even atomic numbers are always more abundant than neighboring lanthanides with odd atomic numbers.

In Figure 4, Masuda-Coryell plots [16,17] are shown for the REEs in the three coal fly ash specimens used in this study and the REEs in the original coal, for which the contents are taken from Fujita and Arikawa [18]. The relative abundances of the REEs were normalized with the REE contents in CI Chondrite [19]. In all plots, negative europium anomalies, derived from the progress of differentiation and found in various natural rocks, were clearly observed. The trends observed in the plots suggest that the REEs are distributed in the ash components of the original coal and then transferred into coal fly ash particles. Though we cannot directly compare the values of the relative abundances in coal and in the coal fly ash specimens plotted in Figure 4, the relative abundances of REEs in coal fly ash specimens are around 10 times those of REES in the original coals, suggesting that the coal fly ash particles are enriched with most of the REE content because after combustion, the weight of the coal fly ash is usually about one tenth of that of the original coal.

Two routes of the transition of REEs from the original coal to the coal fly ash particles can be considered. The

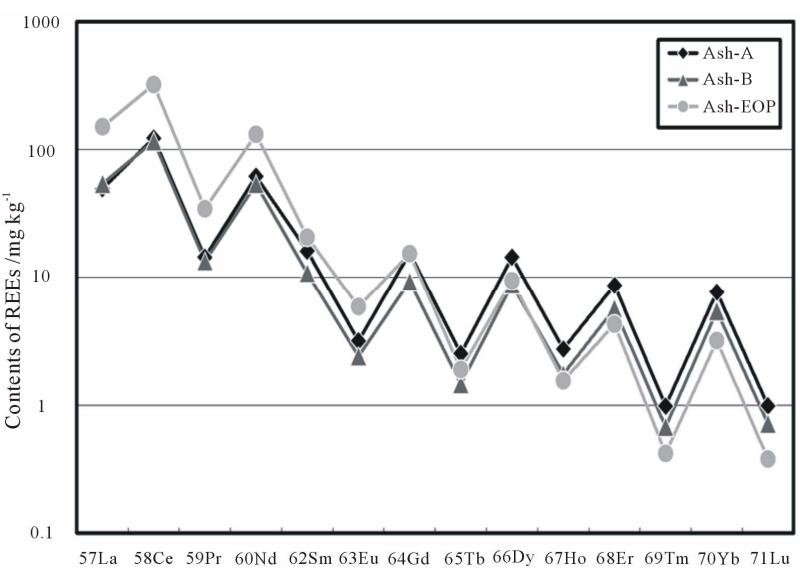

Figure 3. REE contents in coal fly ash specimens in this study.

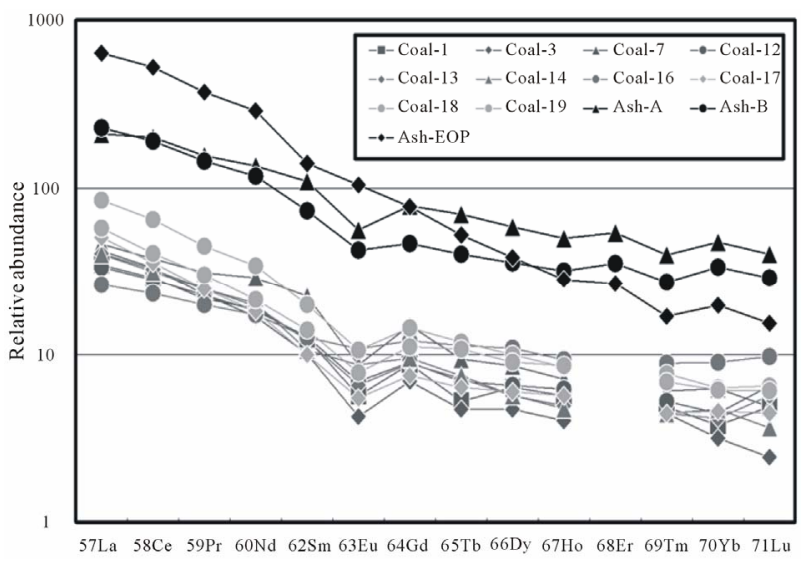

Figure 4. Masuda-Coryell plots for coal fly ash specimens and original coal from the reference.

first is widely known as a "vaporization surface-deposition process" $[20,21]$. Trace elements in the original coals, i.e., the semivolatile compounds [22-24], are vaporized from the original coal during combustion. After the formation of coal fly ash particles, the vaporized elements are deposited onto the surface of these particles.

In order to investigate the probability of vaporization of REEs, thermodynamically stable compounds of REEs were considered using a thermodynamic equilibrium calculation performed using HSC Chemistry 5.1 [25]. In this calculation, europium was selected as a typical REE. Forty-three species, with carbon, hydrogen, oxygen, nitrogen, sulfur, chlorine, fluorine, and europium contents set to their typical values for coal combustion, i.e., 60,30 , $60,220,0.1,0.01,0.002$, and $0.00003 \mathrm{~mol}$, respectively, were selected $[26,27]$. The ash components were ignored in order to focus on the vaporization behavior of europium and simplify the calculation. The total pressure was set to $1 \mathrm{bar}$, and the activity coefficient for each phase was assumed to be unity.

The result of the calculation is shown in Figure 5, 
from which it is confirmed that the volatility of $\mathrm{EuCl}_{3}(\mathrm{~g})$ is much higher than its fluoride, oxide, or elemental vapor. The vaporized $\mathrm{EuCl}_{3}(\mathrm{~g})$ may then be deposited on the surface of coal fly ash particles.

\subsection{Different Types of Occurrences of REEs in Coal Fly Ash Particles}

The other type of REE transition is their accompaniment of blown-up ash components from the original coal. In this case, REEs were melted with ash components and distributed into the coal fly ash particles, such as quartz $\left(\mathrm{SiO}_{2}\right)$, mullite $\left(3 \mathrm{Al}_{2} \mathrm{O}_{3} \cdot 2 \mathrm{SiO}_{2}\right)$, and an amorphous phase. Since coal fly ash particles appeared to be spherical and consisted of a glassy phase together with crystalline phases, such as quartz and mullite, we have assumed both types of occurrences of REEs, namely surfacedeposition and accompaniment. From this assump tion, the dissolution behavior of REEs in a dilute $\mathrm{H}_{2} \mathrm{SO}_{4}$ solvent was fitted using the unreacted core model [28]. Coal fly ash particles were assumed to be spherical particles with uniform sizes. If we assume the occurrence of a diffusion process in the reacted layer or a chemical reaction at the surface of the unreacted core as a rate-determining step, then the following well-known rate equations are obtained.

$$
\begin{aligned}
& \left(\frac{\mathrm{d} n}{\mathrm{~d} t}\right)_{D}=4 \pi r D \frac{\mathrm{d} C_{a}}{\mathrm{~d} r} \quad \text { interlayer diffusion control) } \\
& \left(\frac{\mathrm{d} n_{i}}{\mathrm{~d} t}\right)_{C}=4 \pi r^{2} k_{c} C_{a} \quad \text { (interfacial reaction control) }
\end{aligned}
$$

Here, $n_{i}, t, \mathrm{D}, \mathrm{C}_{\mathrm{a}}, r$, and $k_{c}$ denote the number of moles of unreacted element $i$ (mol), leaching time (s), diffusion coefficient $\left(\mathrm{m}_{2} \cdot \mathrm{s}^{-1}\right)$, acid concentration $\left(\mathrm{mol} \cdot \mathrm{L}^{-1}\right)$, radius of the unreacted core $(\mathrm{m})$, and interfacial reaction rate constant $\left(\mathrm{m} \cdot \mathrm{s}^{-1}\right)$, respectively. By integrating and rearranging Equations (2) and (3), the following well-known rate equations are obtained.

$$
\begin{gathered}
3\left\{1-(1-\mathrm{f})^{2 / 3}\right\}-2 \mathrm{f}=\text { at } \quad \text { (interlayer diffusion control)(4) } \\
1-(1-\mathrm{f})^{1 / 3}=\mathrm{bt} \quad \text { (interfacial reaction control) }(5)
\end{gathered}
$$

Here, $a$ and $b$ are defined as the inverse of the termination times of the reactions, and we can treat them as proportionality constants. Figure 6 shows the fitting results for the dissolution of lanthanum as a typical example. When we assume their dissolution is controlled by interlayer diffusion, the unreacted core model can fit the dissolution rate very well with a variance greater than 0.87 . The intercepts of all of the fitting lines are non-zero. Similar trends are found in the case of the rest of the REEs considered in this study. Therefore, these fitting lines suggest two types of occurrences of REEs, i.e., in

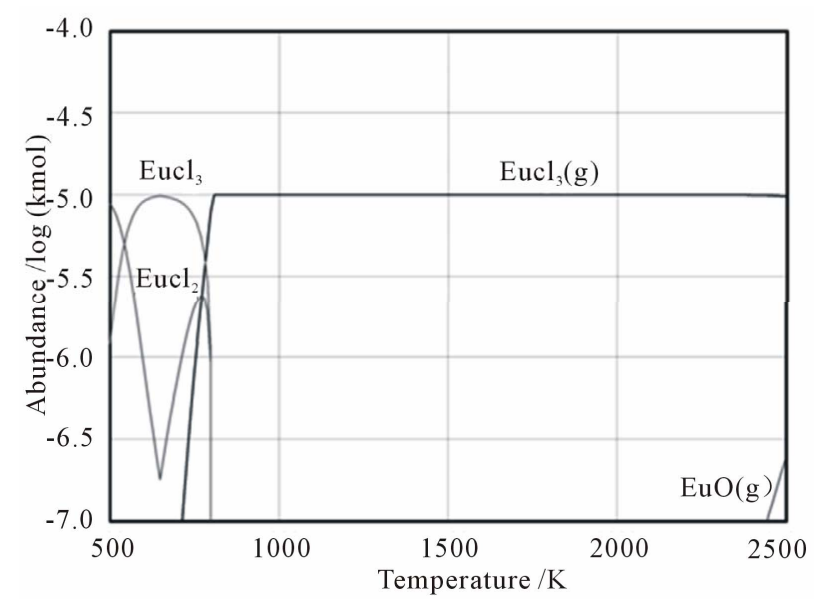

Figure 5. The result of thermodynamic equilibrium calculations for several europium species in coal.

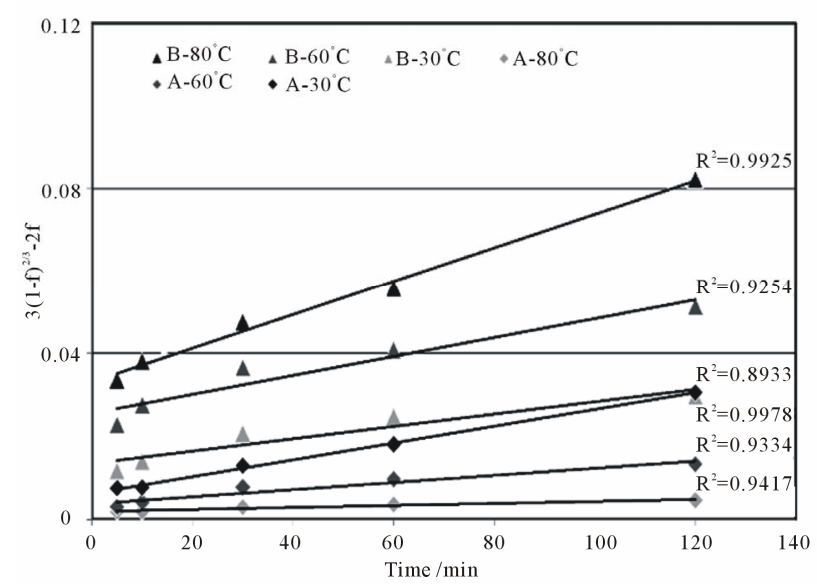

Figure 6. Dissolution rates of lanthanum in a dilute $\mathrm{H}_{2} \mathrm{SO}_{4}$ solvent fitted by the unreacted-core model assuming that dissolution is controlled by interlayer diffusion.

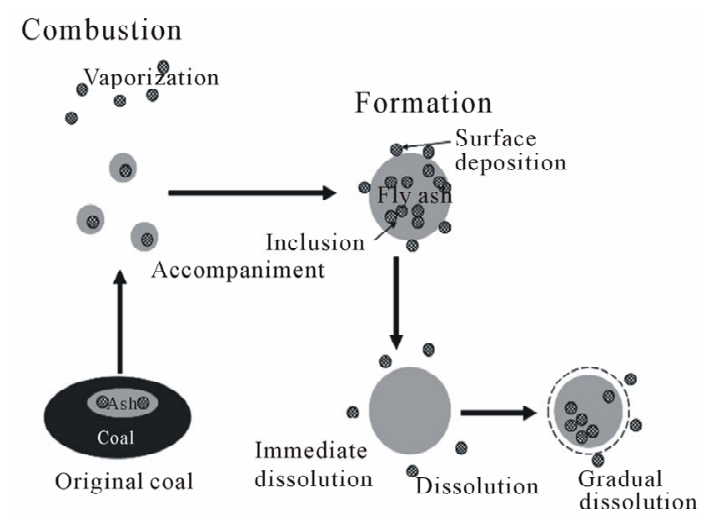

Figure 7. The estimated pass of REEs.

the early stages of dissolution, REEs at the surface of the coal fly ash dissolve immediately, resulting in the drastic increase in the $\left(3(1-f)^{2 / 3}-2 f\right)$ value. Thereafter, REEs inside the coal fly ash particles dissolve gradually, cor- 
responding to the linearity of the fitting line.

The estimated transition pass of REEs through coal combustion and dissolution in $\mathrm{H}_{2} \mathrm{SO}_{4}$ were described in Figure 7, where the REEs were drawn as checked circle The degree of "surface-deposition" and "accompaniment" will be greatly affected by the type of the original coal and combustion conditions, including temperature, oxygen concentration, residence time, and cooling rate of coal fly ash particles, and their effects on the degree of each type of occurrences of REEs will be investigated in future work.

\section{Conclusion}

A Laboratory-scale dissolution experiments were conducted to determine REE contents in coal fly ash particles and investigate their dissolution behavior in $\mathrm{H}_{2} \mathrm{SO}_{4}$ solvents. The REE contents were precisely determined by comparing the results with IRANT EOP, which were considered as the benchmark for accuracy. In the dissolution tests, dissolution rates of REEs increased with the temperature of the $\mathrm{H}_{2} \mathrm{SO}_{4}$ solvent. The REE content in coal fly ash specimens completely conformed to OddoHarkins rule, and the Masuda-Coryel plots show that most of them are probably derived from the ash component of the original coal. The transition of the REEs was attributed to surface deposition and accompaniment, and the probabilities of both processes could be explained by applying the unreacted core model to the dissolution behavior of REEs from coal fly ash in $\mathrm{H}_{2} \mathrm{SO}_{4}$ solvent.

\section{Acknowledgements}

The authors would like to express their sincere gratitude to the Grant-in-Aid for Scientific Research (KAKENHI) 23760710 from the Ministry of Education, Culture, Sports, Science and Technology, Japan, and to the Steel Foundation for Environmental Protection Technology for their financial support. We also acknowledge the Technical Division, School of Engineering, Tohoku University, and the Analytical Research Core for Advanced Materials, Institute for Materials Research, Tohoku University, for facilitating the ICP-MS measurements.

\section{REFERENCES}

[1] Japan Coal Energy Center, "Coal Ash Database". http://www.jcoal.or.jp/coalash/coalash.html

[2] Societies of Civil Engineers, "The Technologies about Effective Utilization for Coal Fly Ash Aiming for the Sound Material-Cycle Society," Japan, 2003. http://www.jsce.or.jp/committee/enedobo/text/03.pdf

[3] Ministry of the Environment, "Environmental Basic Act," Japan, 1993.

http://law.e-gov.go.jp/htmldata/H05/H05HO091.html

[4] M. Xu, R. Yan, C. Zheng, Y. Qiao, J. Han and C. Sheng,
"Status of Trace Element Emission in a Coal Combustion Process: A Review," Fuel Processing Technology, Vol. 85, No. 2-3, 2003, pp. 215-237.

[5] Ministry of the Environment, "Fundamental Law for Establishing a Sound Material-Cycle Society," Japan, 2000. http://law.e-gov.go.jp/htmldata/H12/H12HO110.html

[6] Ministry of the Environment, "Soil Contamination Countermeasures Act," Japan, 2002.

http://law.e-gov.go.jp/htmldata/H14/H14HO053.html

[7] S. Kashiwakura, H. Kubo, Y. Kumagai, H. Kubo, K. Matsubae-Yokoyama, K. Nakajima and T. Nagasaka, "Removal of Boron from Coal Fly Ash by Washing with $\mathrm{HCl}$ Solution", Fuel, Vol. 88, No. 7, 2009, pp. 1245-1250. doi:10.1016/j.fuel.2008.12.027

[8] S. Kashiwakura, H. Ohno, K. Matsubae-Yokoyama, Y. Kumagai, H. Kubo and T. Nagasaka, "Removal of Arsenic in Coal Fly Ash by Acid Washing Process Using Dilute $\mathrm{H}_{2} \mathrm{SO}_{4}$ Solvent," Journal of Hazardous Materials, Vol. 181, No. 1-3, 2010, pp. 419-425.

doi:10.1016/j.jhazmat.2010.05.027

[9] S. Kashiwakura, H. Ohno, Y. Kumagai, H. Kubo, K. Matsubae and T. Nagasaka, "Dissolution Behavior of Selenium from Coal Fly Ash Particles for the Development of an Acid-Washing Process," Chemosphere, Vol. 85, No. 4, 2011, pp. 598-602. doi:10.1016/j.chemosphere.2011.06.099

[10] JOGMEC, "Material Flow of Mineral Resources," 2010. http://www.jogmec.go.jp/mric_web/jouhou/material/2010 /REE.pdf

[11] Z. X. Yuan, C. Y. Wu, L. M. Xu and Y. X. Ni, "The Distribution of Trace Elements in Granitoids in the Nanling Region of China," Chinese Journal of Geochemistry, Vol. 12, No. 3, 1993, pp. 193-205. doi:10.1007/BF02843359

[12] S. Kashiwakura, T. Takahashi, H. Maekawa and T. Nagasaka, "Application of 11B MAS-NMR to the Characterization of Boron in Coal Fly Ash Generated from Nantun Coal," Fuel, Vol. 89, No. 5, 2010, pp. 1006-1011. doi:10.1016/j.fuel.2009.10.028

[13] S. Iwata, K. Minamoto, E. Fujimori, K. Chiba and H. Haraguchi, "Determination of Rare Earth Elements in Industrial Waste Incineration Fly Ash by ICP-MS and the Characteristics of the Rare-Earth Element Distribution Pattern (in Japanese)," BUNSEKI KAGAKU, Vol. 50, No. 6, 2001, pp. 419-425. doi:10.2116/bunsekikagaku.50.419

[14] R. R. Greenberg, E. A. Mackey and D. A. Becker, "The Application of Instrumental Neutron Activation Analysis for the Certification of the New NIST Fly Ash SRM," Journal of Radioanalytical and Nuclear Chemistry, Vol. 193, No. 1, 1995, pp. 7-14. doi:10.1007/BF02041911

[15] I. Roelandts and E. S. Gladney, "Consensus Values for NIST Biological and Environmental Standard Reference Materials," Fresenius Journal of Analytical Chemistry, Vol. 360, No. 3-4, 1998, pp. 327-338. doi:10.1007/s002160050704

[16] A. Masuda, "Regularities in Variation of Relative Abundances of Lanthanide Elements and an Attempt to Analyse Separation-Index Patterns of Some Minerals," The Journal of Earth Sciences, Nagoya University, Vol. 10, No. 2, 1962, pp. 173-187. 
[17] C. D. Coryell, J. W. Chase and J. W. Winchester, "A Procedure for Geochemical Interpretation of Terrestrial Rare-Earth Abundances Patterns," Journal of Geophysical Research, Vol. 68, No. 2, 1963, pp. 559-566. doi:10.1029/JZ068i002p00559

[18] K. Fujita and Y. Arikawa, "Determination of Rare Earth Elements in Coal Samples by ICP-MS," The Bulletin of Japan Women's University, Vol. 14, 2006, pp. 7-11.

[19] W. McDonough and S. Sun, "The Composition of the Earth," Chemical Geology, Vol. 130, No. 3-4, 1995, pp. 223-253. doi:10.1016/0009-2541(94)00140-4

[20] R. L. Davison, D. F. S. Natusch, J. R. Wallace and C. Evans Jr, "Trace Elements in Fly Ash. Dependence of Concentration on Particle Size," Environmental Science \& Technology., Vol. 8, No. 13, 1974, pp. 1107-1113. doi:10.1021/es60098a003

[21] K. C. Galbreath, D. L. Toman, C. J. Zygarlicke and J. H. Pavlish, "Trace Element Partitioning and Transformations during Combustion of Bituminous and Subbituminous U. S. Coals in a 7-kW Combustion System," Energy \& Fuel, Vol. 14, No. 6, 2000, pp. 1265-1279. doi:10.1021/ef000105n

[22] R. Meij, "Trace Element Behavior in Coal-Fired Power Plants," Fuel Processing Technology, Vol. 39, No. 1-3, 1994, pp. 199-217. doi:10.1016/0378-3820(94)90180-5
[23] R. Meij and H. Winkel, "The Emissions of Heavy Metals and Persistent Organic Pollutants from Modern CoalFired Power Stations," Atmospheric Environment, Vol. 41, No. 40, 2007, pp. 9262-9272. doi:10.1016/j.atmosenv.2007.04.042

[24] S. Kashiwakura, T. Takahashi and T. Nagasaka, "Vaporization Behavior of Boron from Standard Coals in the Early Stage of Combustion," Fuel, Vol. 90, No. 4, 2011, pp. 1408-1415. doi:10.1016/j.fuel.2010.12.029

[25] A. Roine, "Outokumpu HSC Chemistry for Windows, Version 5.1," 2002.

[26] N. Tsubouchi, Y. Wang and Y. Ohtsuka, "Fate of the Chlorine in Coal during Temperature-Programmed Pyrolysis," The proceedings of the Japan Institute of Energy, Vol. 40, 2003, pp. 124-125 (in Japanese).

[27] N. Tsubouchi, H. Hayashi and Y. Ohtsuka, "Functional Forms of the Fluorine and Carbon in Fly Ashes Formed in Pulverized Coal Combustion," The proceedings of the Japan Institute of Energy, Vol. 42, 2005, pp. 59-60 (in Japanese).

[28] S. Yagi and D. Kunii, "Fluidized-Solids Reactors with Continuous Solid Feed-I: Residence Time of Particles in Fluidized Beds," Chemical Engineering Science, Vol. 16, No. 3-4, 1961, pp. 364-371. doi:10.1016/0009-2509(61)80043-2 